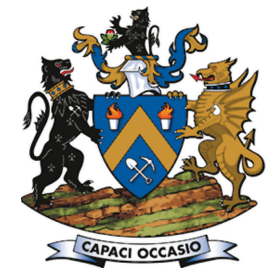

Affiliation:

'Water Pollution Monitoring and Remediation Initiatives Research Group in the School of Chemical and Minerals Engineering of the North West University, Potchefstroom, South Africa. ${ }^{2}$ Coal beneficiation Research Group in the School of Chemical and Minerals Engineering of the North West University, Potchefstroom, South Africa.

Correspondence to:

E. Fosso-Kankeu

Email:

Elvis.FossoKankeu@nwu.ac.za elvisfosso.ef@gmail.com

Dates:

Received: 19 Nov. 2018

Revised: 28 Feb. 2019

Accepted: 7 Mar. 2019

Published: July 2019

How to cite:

Fosso-Kankeu, E., Weideman, R., Moyakhe, D., Waanders, F.B.,

Le Roux, M., and Campbell, Q.P. Hydrothermal preparation of biochar from spent coffee grounds, and its application for the removal of cadmium from coal tailings leachate.

The Southern African Insitute of Mining and Metallurgy

DOI ID:

http://dx.doi.org/10.17159/24119717/449/2019

ORCiD ID:

E. Fosso-Kankeu

https://orchid.org/0000-0002-

7710-4401

\section{Hydrothermal preparation of biochar from spent coffee grounds, and its application for the removal of cadmium from coal tailings leachate}

\author{
E. Fosso-Kankeu ${ }^{1}$, R. Weideman ${ }^{1}$, D. Moyakhe1, F.B. Waanders ${ }^{1}$, \\ M. Le Roux ${ }^{2}$, and Q.P. Campbell ${ }^{2}$
}
"Paper written on project work carried out in partial fulfilment of B.Eng (Chemical Engineering) degree

\section{Synopsis}

Spent coffee grounds were transformed into biochar using a hydrothermal method. Some of the biochar product was pre-treated through surfactant impregnation with sodium dodecyl sulphate (SDS) to enhance its adsorption capacity. The non-treated(NT) and pre-treated(PT) biochars were characterized using FTIR spectroscopy and SEM-EDS analyses, which revealed that the products had the potential for adsorption of heavy metals from solution and confirmed the successful impregnation of biochar with SDS surfactant. The two adsorbents were then used for the removal of cadmium from solution and the adsorption behavior and capacity determined through adsorption isotherm, kinetic, and thermodynamic studies. It was found that the cadmium was adsorbed in several concentric layers on the surface of the adsorbents through a chemisorption mechanism. The PT biochar was identified as a superior adsorbent, with a capacity of $q_{e}=10.67 \mathrm{mg} / \mathrm{g}$ compared to the NT biochar with $q_{e}=4.82 \mathrm{mg} / \mathrm{g}$. The adsorption of cadmium onto the PT biochar was further determined to be spontaneous and endothermic. It was therefore concluded that the PT biochar shows potential as an adsorbent and could be considered for implementation in the treatment of metal-polluted effluents.

\section{Keywords}

spent coffee grounds, biochar, surfactant impregnation, cadmium, coal tailings leachate, adsorption.

\section{Introduction}

Coal mining operations are notorious for producing large amounts of waste tailings, which are disposed of in the form of a slurry on tailings dams. This inadvertently contributes towards environmental problems (Jin, Mansour, and Thomas, 2017). Heavy metals are one of the most common pollutants that originate from solid mine waste disposal facilities, and these can leach into groundwater supplies, contaminating them and rendering the water unsuited for human consumption (Salomons, 1995). Cadmium occurs in conjunction with metalliferous ores and can cause severe damage to agricultural soils and drinking water supplies in the vicinity of mining sites (Dudka et al., 1995). It has a tendency to migrate into the surrounding vegetation, which in turn can cause harm to humans and animals when consumed (Marquez et al., 2018).

Precipitation and coagulation methods are widely used to remove heavy metals from aqueous solutions. The drawback of these processes is that they generates large amounts of low-density aerated sludge, which give rise to dewatering and disposal problems (Fu and Wang, 2011). Membrane filtration is another very effective method for removing heavy metals from wastewater. A huge disadvantage of this technology is the high costs involved. That said, the method is still widely considered due to it is simplicity and flexibility in plant design and operation (Fu and Wang, 2011). Other methods for the removal of heavy metals from solutions include ion exchange, electrodeposition, reverse osmosis, and electroplating (Redwscu and Nicolae, 2012). The implementation of all these processes is hindered by the high capital and/or operational costs involved.

Adsorption is an effective and economical way to remove heavy metals from wastewater. Due to adsorption being reversible in some cases, it is possible to regenerate the adsorbent by stripping of the 


\section{Hydrothermal preparation of biochar from spent coffee grounds, and its application}

adsorbed species and re-using it (Fu and Wang, 2011). Activated carbon (AC) is a widely used adsorbent for the removal of heavy metals from solution in the wastewater treatment sector (Jusoh et al., 2007; Kang et al., 2008). The main concern with activated carbon is that it remains an expensive material, with prices still on the increase.

An alternative adsorption method makes use of biochar for the removal of heavy metals from wastewater. The benefits of using biochar include its low production costs, availability of a wide range of feedstocks, diversity of the biochar with each type of feedstock, and mechanical and thermal stability (Mohan et al., 2015). Biochar can be produced using organic materials as a feedstock. One of these materials is spent coffee grounds. Over 120 million bags of coffee are produced worldwide each year, which correspond to $7 \mathrm{Mt}$ of coffee waste (Zuorro and Lavecchia, 2012). These spent coffee grounds have no commercial value and are usually sent to compost facilities for disposal (Zuorro and Lavecchia, 2012). This makes spent coffee grounds an abundant feedstock available for the production of biochar. To improve the adsorption capabilities of the char, sodium dodecyl sulphate (SDS) is impregnated on the surface of the char by means of a physico-chemical pretreatment process. The addition of SDS will increase the amount of potential bonds on the char's surface, which may lead to an improvement of its sorption capacity (Fosso-Kankeu et al., 2017a).

\section{Experimental}

\section{Biochar production}

A slurry of spent coffee grounds was prepared for a $3 \mathrm{vol} \%$ biomass loading. The slurry was mixed with reverse osmosis (RO) water to produce $60 \mathrm{~L}$ of solution. RO water is used instead of tap water to prevent damage to the stainless steel inside the reactor due to the high chlorine content of normal tap water. The slurry was then soaked overnight.

The hydrothermal liquefaction (HTL) reactor tanks were filled with $60 \mathrm{~L}$ of slurry, sealed, and pressurized with nitrogen gas (baseline 5.0 bar) to 90 bar, and the reactor temperature was increased to $305^{\circ} \mathrm{C}$. As soon as the reactor reached target temperature the flow of slurry from the tanks to the reactor was set to $120 \mathrm{~L} / \mathrm{h}$. This gave the slurry a residence time of 10 minutes inside the $20 \mathrm{~L}$ reactor vessel.

After all the slurry had flowed through the reactor it was switched off and left to cool overnight. The tanks were then depressurized and the product was sampled.

The HTL plant product is a mixture of an aqueous oil phase and biochar solid phase. The biocrude was separated from the aqueous phase by pressure filtration. The filtered biocrude was then dissolved in acetone to separate it from the biochar. This was done by reacting the biocrude in a $1 \mathrm{~L}$ Erlenmeyer flask with $1 \mathrm{~L}$ acetone for 48 hours on a magnetic stirrer. This process was repeated to ensure maximum removal of oil from the char, which increased the porosity of the biochar. The product biochar was finally separated from the acetone solution in a Büchner filter and dried for 12 hours at $105^{\circ} \mathrm{C}$. The dried biochar was crushed to a particle size less than $250 \mu \mathrm{m}$ using a ceramic mill.

\section{Biochar pre-treatment}

The biochar was impregnated with sodium dodecyl sulphate (SDS) by adding $10 \mathrm{~g}$ of biochar to $1 \mathrm{~L}$ SDS solution $(10 \mathrm{~g} / \mathrm{L})$; the mixture was incubated and stirred at $120 \mathrm{r} / \mathrm{min}$ for 24 hours at $60^{\circ} \mathrm{C}$. The solution was then filtered by Büchner filtration.
The biochar was then dried at $65^{\circ} \mathrm{C}$ for 12 hours, and the dried biochar was crushed to finer particles using a ceramic bowl.

\section{Characterization of the biochar}

Both biochars were characterized by Fourier transform infrared spectroscopy (FTIR) using an IRAffinity-1S instrument from Shimadzu. The spectrometer had a spectral range from 4000 to $400 \mathrm{~cm}^{-1}$. This process was used to identify the functional groups of the biochars. The surface morphology of each adsorbent was determined using scanning electron microscopy (SEM) photography (TESCAN, VEGA SEM) under a $20 \mathrm{kV}$ electron acceleration voltage coupled with energy-dispersive X-ray spectroscopy (EDS) for elemental analysis (Fosso-Kankeu et al., 2015).

\section{Adsorption experiments}

All the adsorption experiments were carried out in a batch system. The biochar dosage was fixed at $0.2 \mathrm{~g}$ per $50 \mathrm{~mL}$ solution. The adsorption capabilities of treated and untreated biochar were tested, thus two sets of adsorbents were tested for each experiment. The variables tested included the sorption contact time, initial cadmium concentration, and water temperature. Finally, coal tailings leachates were used to determine the real-time adsorption behaviour of the biochar.

\section{Effect of contact time}

A $250 \mathrm{~mL}$ flask containing $0.2 \mathrm{~g}$ adsorbent and $50 \mathrm{ppm}$ cadmium in $50 \mathrm{~mL}$ of aqueous solution was incubated at $25^{\circ} \mathrm{C}$. The flask was continuously stirred by shaking it at a speed of $120 \mathrm{r} / \mathrm{min}$ for $15,30,45,60,120,180$, and 240 minutes to assess the effect of time on the adsorption of cadmium onto the different biochars.

\section{Effect of initial cadmium concentration}

The second set of experiments was carried out to determine the adsorption capability of the biochars at different initial cadmium concentrations. The same set-up was repeated, only this time using a one-hour residence time for the chars in the solution while varying the initial cadmium concentration from $10 \mathrm{ppm}$ to 70 ppm at 10 ppm intervals.

\section{Effect of temperature}

The process was again repeated with a residence time of one hour and initial cadmium concentration of $50 \mathrm{ppm}$. The temperature of the solution was increased to $35^{\circ} \mathrm{C}, 45^{\circ} \mathrm{C}$, and $55^{\circ} \mathrm{C}$.

\section{Adsorption of cadmium from the coal tailings leachate}

The last set of adsorption experiments was carried out to determine the biochar adsorption capability when exposed to a multi-metal solution. The total metal concentration of a coal tailings leachate was adjusted to 100,200 , and $250 \mathrm{ppm}$ and spiked with cadmium (30 ppm). These solutions were exposed to $0.2 \mathrm{~g}$ of the various biochars and the adsorption process was carried out as described in the first set of adsorption experiments while keeping the contact time at 1 hour.

After the adsorption process, an aliquot of $20 \mathrm{~mL}$ solution was then placed in $50 \mathrm{~mL}$ centrifuge tubes. The tubes were centrifuged at $4000 \mathrm{r} / \mathrm{min}$ for 10 minutes, after which the biochar was separated from the solution. The supernatant solution was then poured into a new tube for analysis by inductively coupled plasma - optical emission spectrometry (ICP-OES) (ICP Expert II, Agilent Technologies 720 to determine the concentration of the residual cadmium in solution. 


\section{Hydrothermal preparation of biochar from spent coffee grounds, and its application}

\section{Results and discussion}

\section{Characterization of adsorbents}

\section{FTIR spectra}

The spectra of the treated and untreated biochars (Figure 1) show almost the same pattern of peaks. Significant peaks were observed in the range $2100-2200 \mathrm{~cm}^{-1}$, which can be ascribed to the presence of adsorbent group $C \equiv C$ deriving from the alkyne functional group. The peak at $2650 \mathrm{~cm}^{-1}$ suggests the formation of formic acid dominated by the carboxylic group, which plays an important role in the binding of metals. Important binding groups such as $\mathrm{C}-\mathrm{H}$ stretch and $\mathrm{C}=\mathrm{O}$ can relate and play significant roles during the adsorption process (Kantcheva, 2003).

\section{SEM-EDS}

SEM-EDS analysis was done to determine if the treatment with SDS was successful by comparing the surface areas available for adsorption on the two biochars. The results of these analyses are shown in Figures 2 and 3 and Tables I and II.

A comparison of the elemental weight percentages between the NT biochar and PT biochar, as indicated in Tables I and II, shows an increase in sodium from $0 \%_{\mathrm{wt}}$ to $0.3 \%_{\mathrm{wt}}$ and for sulphur from $0.12 \%$ wt to $1.44 \%_{w t}$. This indicated that the impregnation with SDS was a success, leaving the PT biochar with a coarser outer surface compared to the NT biochar. This change in surface

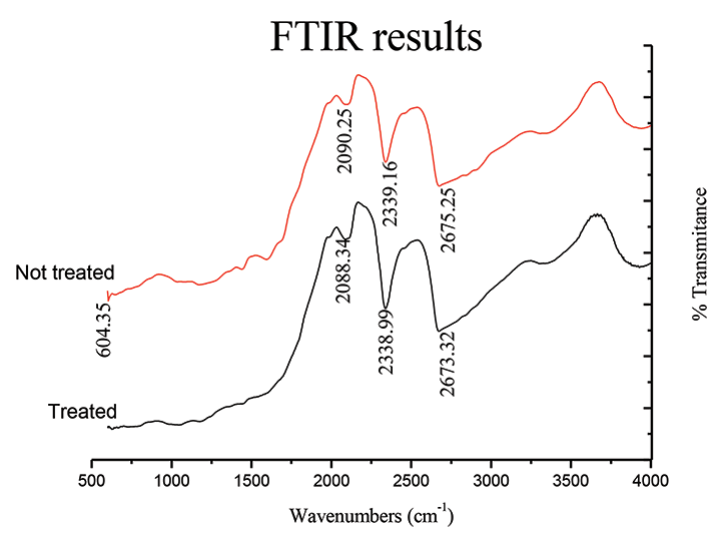

Figure 1-FTIR spectra of untreated and treated biochar

structure can be attributed mainly to sulphur loading onto the biochar.

\section{Adsorption effectiveness}

Figure 4 shows the SEM-EDS spectra of the NT and PT biochars after exposure to cadmium in solution. When these spectra are compared with those for the pure biochars in Figures 2 and 3 respectively, the presence of cadmium in the spectra is clear. This confirms the ability of both biochars to adsorb cadmium from an aqueous solution.

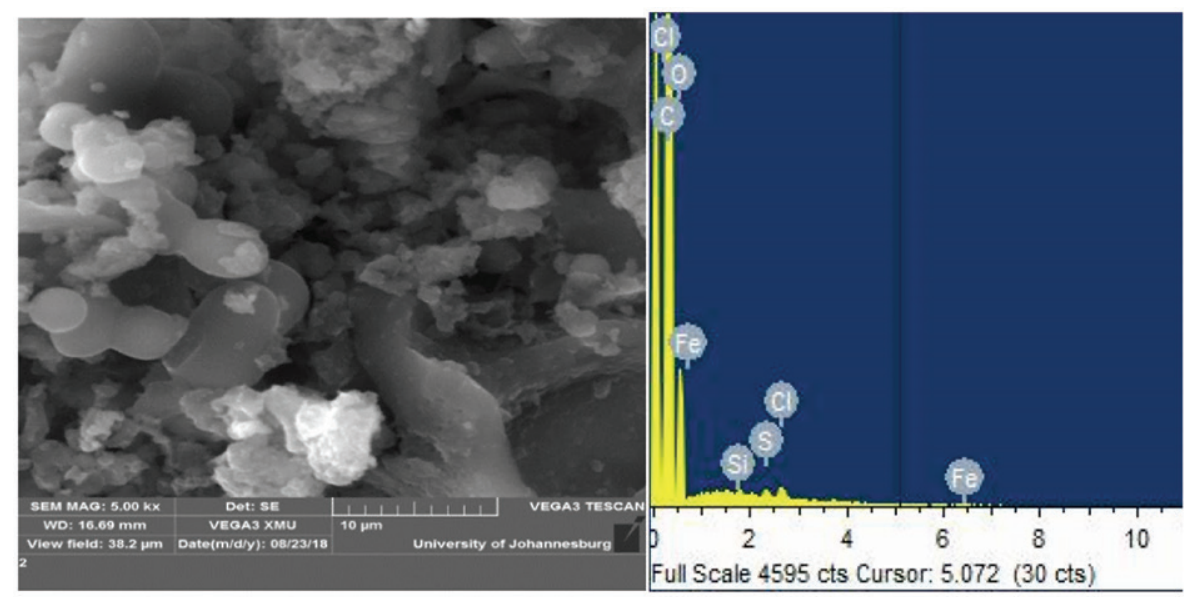

Figure 2-SEM-EDS of NT biochar

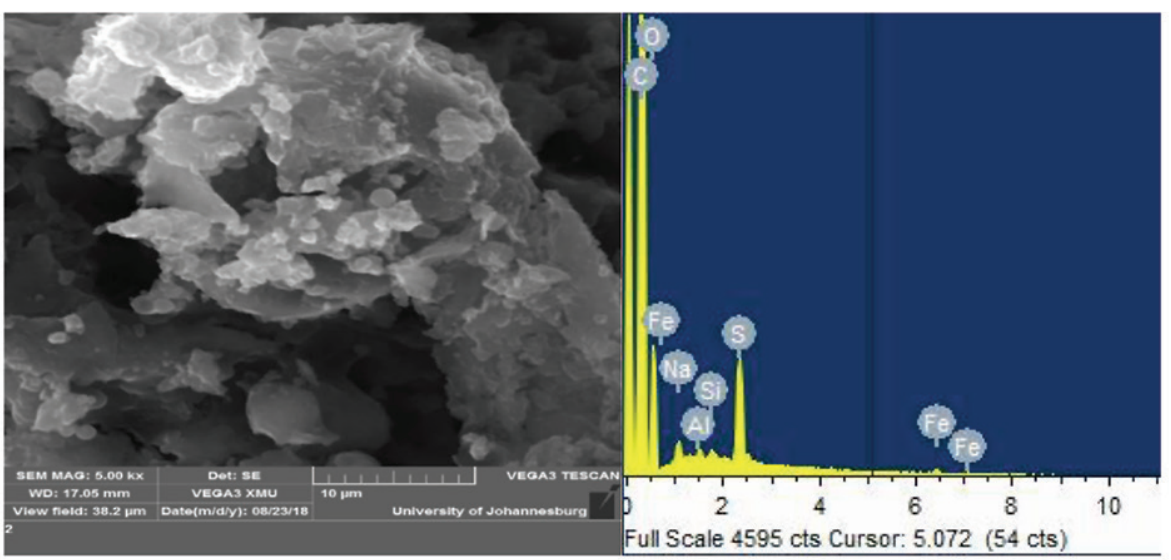




\section{Hydrothermal preparation of biochar from spent coffee grounds, and its application}

\begin{tabular}{|l|c|c|}
\hline $\begin{array}{l}|l| \\
\text { Table I } \\
\text { EDS results NT biochar }\end{array}$ \\
\hline Element & Weight \% & Atomic \% \\
\hline $\mathrm{C}$ & 82.67 & 86.61 \\
$\mathrm{O}$ & 16.80 & 13.21 \\
$\mathrm{Si}$ & 0.06 & 0.03 \\
$\mathrm{~S}$ & 0.12 & 0.05 \\
$\mathrm{Cl}$ & 0.2 & 0.07 \\
Fe K & 0.14 & 0.03 \\
\hline
\end{tabular}

\begin{tabular}{|c|c|c|}
\hline \multicolumn{3}{|c|}{$\begin{array}{l}\text { Table II } \\
\text { EDS results of PT biochar }\end{array}$} \\
\hline Element & Weight \% & Atomic \% \\
\hline C & 82.91 & 87.31 \\
\hline 0 & 14.97 & 11.83 \\
\hline $\mathrm{Na}$ & 0.30 & 0.17 \\
\hline $\mathrm{Al}$ & 0.08 & 0.04 \\
\hline $\mathrm{Si}$ & 0.09 & 0.04 \\
\hline S K & 1.44 & 0.57 \\
\hline Fe K & 0.21 & 0.05 \\
\hline
\end{tabular}

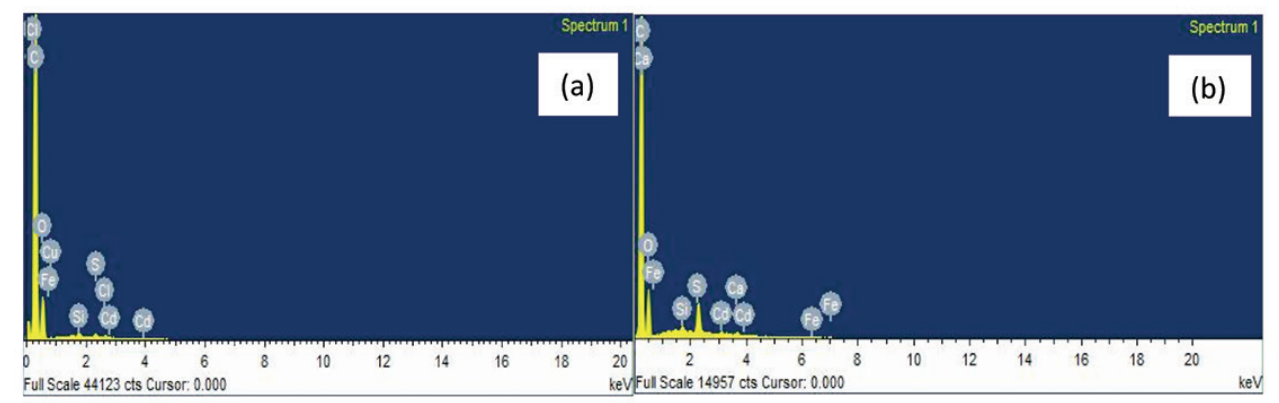

Figure 4-SEM-EDS of (a) NT biochar and (b) PT biochar post cadmium exposure
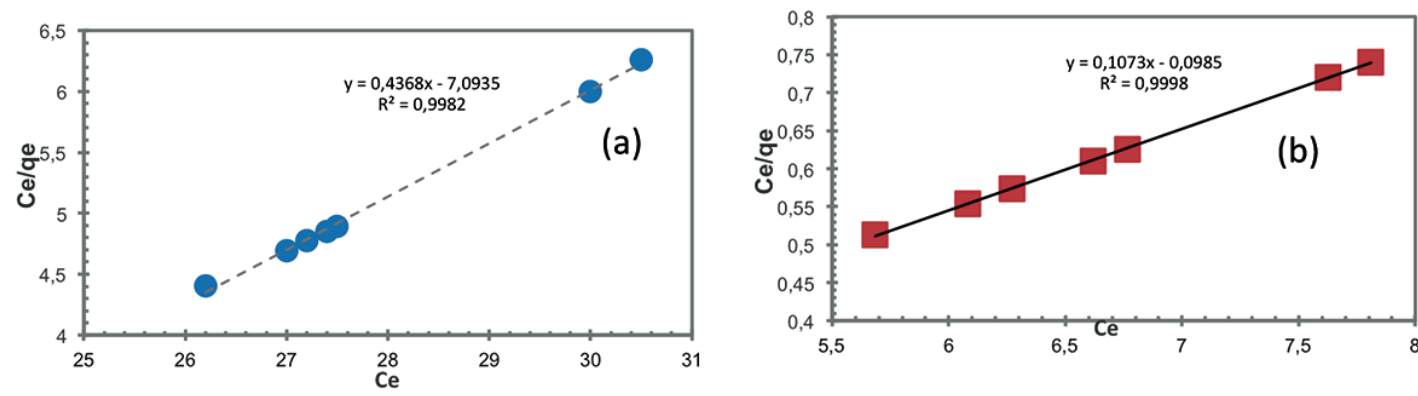

Figure 5-Validation of the Langmuir isotherm model for adsorption of Cd onto (a) NT biochar and (b) PT biochar

\section{Isotherm and kinetic models}

The Langmuir and Freundlich isotherms were used to determine the adsorption mechanisms of the two biochars. This was done by determining the equilibrium concentration of cadmium after one hour of adsorption, starting at various initial cadmium concentrations, and plotting either $C_{e} / q_{e} v s C_{e}$ or $\log q_{e} v s \log C_{e}$, for the two different isotherms respectively.

Figure 5 shows the Langmuir plots for (a) the NT biochar and (b) the PT biochar. From the strong linear relationship of both graphs, the slope and intercept were used to determine the Langmuir constants $q_{m}$ and $b$. These are reported in Table III.

To validate the Freundlich isotherm model, Figures $6 \mathrm{a}$ and $6 \mathrm{~b}$ were constructed by plotting $\log \left(q_{e}\right)$ as a function of $\log \left(C_{e}\right)$; the Freundlich isotherm parameters $n$ and $k_{f}$ were determined from the slope and intercept of the plots respectively. The values obtained are reported in Table III.

From Table III, it can be observed that the coefficient of determination $\left(R^{2}\right)$ in both instances is close to unity, therefore the Langmuir and the Freundlich isotherm models fit the cadmium adsorption equilibrium data for both the treated and untreated biochars. This implies that cadmium attaches to the binding groups on the surface of the chars as well as inside the pores (homogeneous and heterogeneous surfaces) (Yao et al., 2014; Fosso-Kankeu, 2016).

\section{Table III \\ Langmuir and Freundlich constants}

\begin{tabular}{|l|c|c|c|c|c|c|}
\hline \multirow{2}{*}{ Adsorbent } & \multicolumn{3}{|c|}{ Langmuir isotherm } & \multicolumn{3}{c|}{ Freundlich isotherm } \\
\cline { 2 - 7 } & $\left.\boldsymbol{q}_{\boldsymbol{m}} \mathbf{( m g} \mathbf{g}\right)$ & $\boldsymbol{b}$ & $\mathbf{R}^{2}$ & $\mathbf{n}$ & $\boldsymbol{k}_{\boldsymbol{f}}$ & $\mathbf{R}^{\mathbf{2}}$ \\
\hline NT biochar & 2.29 & -0.062 & 0.9982 & -0.75 & 457.9 & 0.9985 \\
PT biochar & 9.3197 & -1.0893 & 0.9998 & -6.4 & 14.6 & 0.9972 \\
\hline
\end{tabular}

Kinetic rate experiments were conducted to validate the pseudo-first and pseudo-second-order kinetics. The adsorption data over time was considered and the kinetic parameters for a pseudo-first-order kinetic model and a pseudo-second-order kinetic model were determined by plotting $\ln \left(q_{e}-q_{t}\right)$ vs $t$ and $t / q$ vs $t$ (Figures $7 \mathrm{a}$ and $\mathrm{b})$, respectively. The kinetic parameters are reported in Table IV.

The ability of the model to predict the adsorption behaviour of the biochar can be determined by considering the coefficient of determination $\left(\mathrm{R}^{2}\right)$. From Table IV, it is clear that the pseudo-second-order model fits the kinetics of both biochar samples, while the pseudo-first-order model is not suitable for the prediction of the reaction kinetics. This implies that the adsorption of cadmium on both adsorbents took place through a chemisorption mechanism. 


\section{Hydrothermal preparation of biochar from spent coffee grounds, and its application}
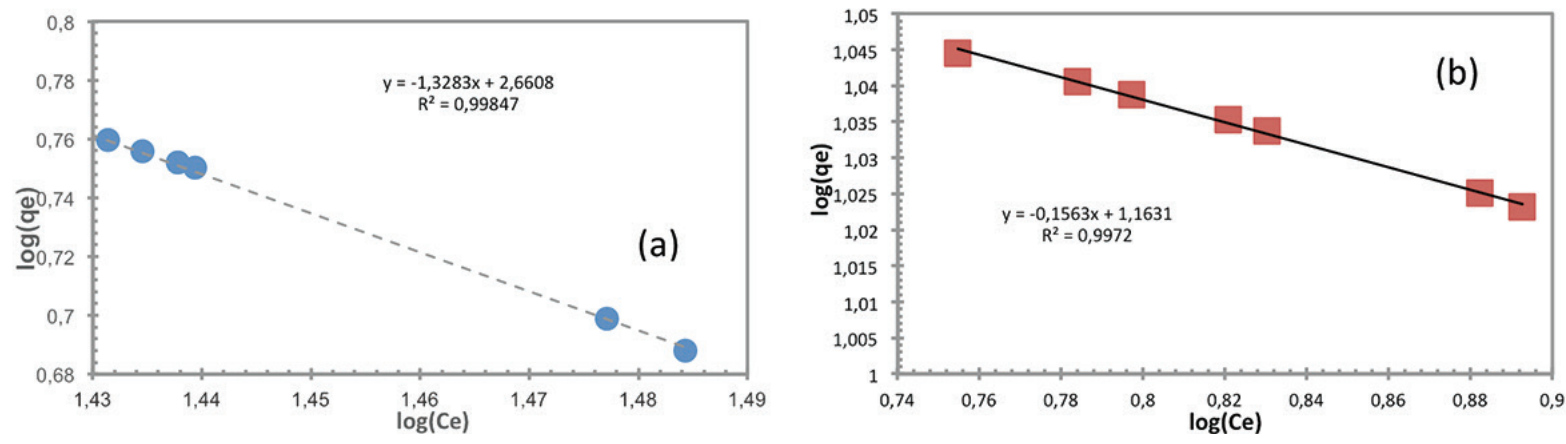

Figure 6-Validation of the Freundlich isotherm model for adsorption of Cd onto (a) NT biochar and (b) PT biochar
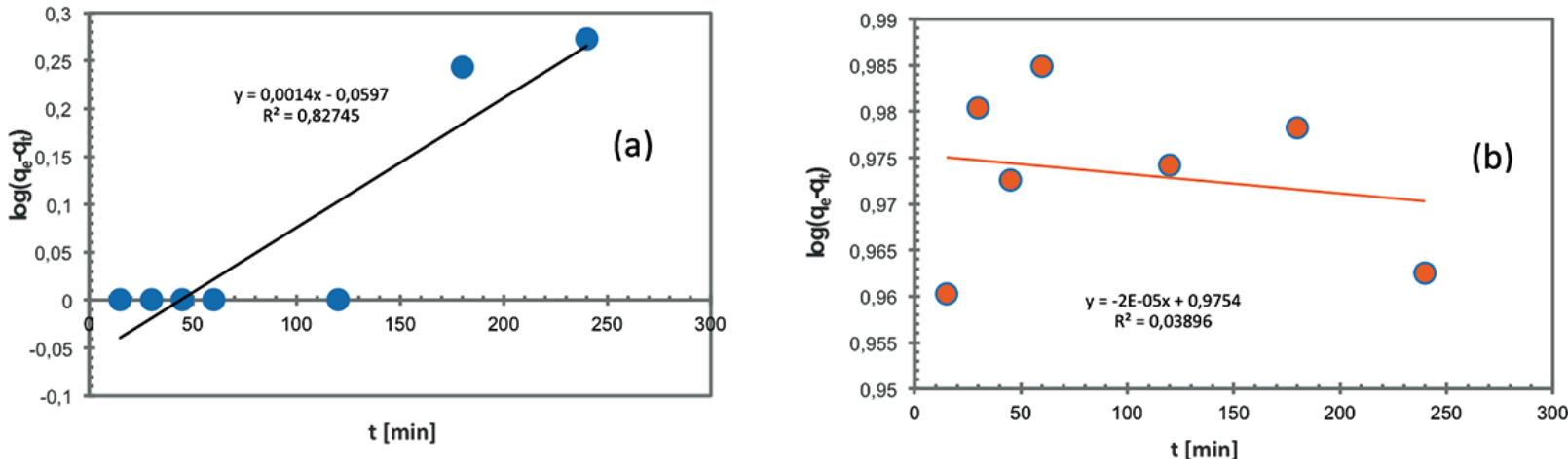

Figure 7-Validation of the pseudo-first-order isotherm model for adsorption of Cd onto (a) NT biochar and (b) PT biochar

Table IV
Pseudo-first and second-order constants
\begin{tabular}{l|c|c|c|c|c|c|}
\hline \multirow{2}{*}{ Adsorbent } & Pseudo-first-order kinetics & \multicolumn{2}{c|}{ Pseudo-second-order kinetics } \\
\cline { 2 - 7 } & $\boldsymbol{q}_{\mathbf{e}}(\mathbf{m g} / \mathbf{g})$ & $\boldsymbol{K}_{1}$ & $\mathbf{R}^{2}$ & $\boldsymbol{q}_{\mathbf{e}}(\mathbf{m g} / \mathbf{g})$ & $\boldsymbol{K}_{\mathbf{2}}$ & $\mathbf{R}^{2}$ \\
\hline NT biochar & 0.8716 & -0.0032 & 0.8275 & 4.8239 & -0.0277 & 0.9953 \\
PT biochar & 9.449 & 0.00005 & 0.039 & 10.6724 & -0.0803 & 0.9995 \\
\hline
\end{tabular}

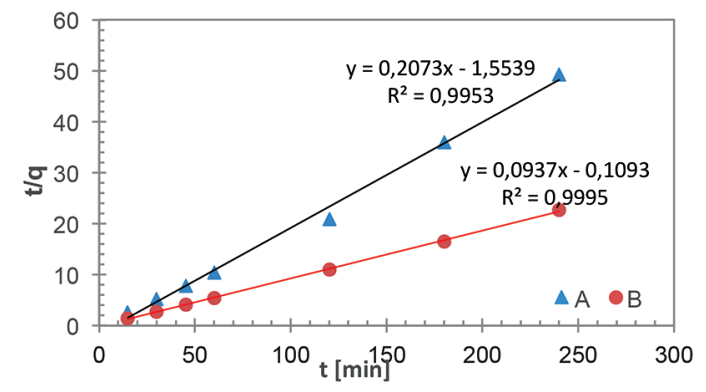

Figure 8-Validation of the pseudo-second-order isotherm model for adsorption of Cd onto (A) NT biochar and (B) PT biochar with SDS

The pseudo-second-order adsorption capacities clearly show that the PT biochar had a higher adsorption capacity, more than double the adsorption capacity of the NT biochar. This shows that the impregnation with SDS was successful, with $q_{e}=10.67 \mathrm{mg} / \mathrm{g}$ compared to the NT biochar with $q_{e}=4.82 \mathrm{mg} / \mathrm{g}$. These results are similar to previous studies reported (Fosso-Kankeu et al., 2017a).

\section{Thermodynamic study}

To evaluate the thermodynamic properties of the biochar, batch adsorption experiments were conducted at three different temperatures $\left(35^{\circ} \mathrm{C}, 45^{\circ} \mathrm{C}\right.$, and $\left.55^{\circ} \mathrm{C}\right)$.
To calculate the enthalpy change, entropy change, and Gibbs free energy the van't Hoff equation was used:

$$
\ln K_{a}=-\frac{\Delta G^{o}}{R T}=-\frac{\Delta H^{o}}{R T}+\frac{\Delta S^{o}}{R}
$$

To determine the thermodynamic properties of the biochar, Figure 9 was constructed by plotting $\ln (q e / C e) v s 1 / T$.

The positive values of the Gibbs free energy of the NT biochar indicate that the adsorption of cadmium on the char was not spontaneous in nature, which is in contrast with the PT biochar where it is clearly spontaneous. In a similar way, it can be showned that in both cases the adsorption of cadmium was endothermic in nature due to the large positive enthalpy values, confirming that the adsorption of cadmium on NT biochar and PT biochar occurred through a chemisorption mechanism (FossoKankeu et al., 2017b ). The positive entropy values obtained for the PT biochar suggest randomness in the solid/liquid interface where there are a few structural changes in the adsorbent and adsorbate for the adsorption of $\mathrm{Cd}$.

\section{Application of biochar for the treatment of coal tailings leachate}

Samples of 100, 200, and 250 ppm dissolved metals in coal leachate were spiked with $30 \mathrm{ppm}$ cadmium then exposed to the different biochars for adsorption. The results are shown in Figure 10.

As seen from Figure 10, at a 100 ppm metal concentration the adsorbent showed the highest affinity for cadmium adsorption from the solution. With increasing total metal concentration the adsorbents' ability to adsorb cadmium decreased significantly due to competition for binding sites on the adsorbents by other metals present in solution. This trend was shown by both the NT and the PT biochar. It is, however, clear that the PT biochar outperformed the NT biochar for each metallic feed concentration, 


\section{Hydrothermal preparation of biochar from spent coffee grounds, and its application}

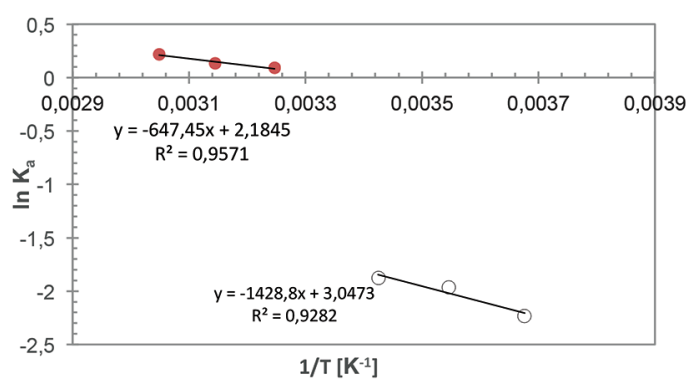

Figure 9-Thermodynamic analysis of the adsorption of Cd with (X) NT biochar, and (Y) PT biochar with SDS

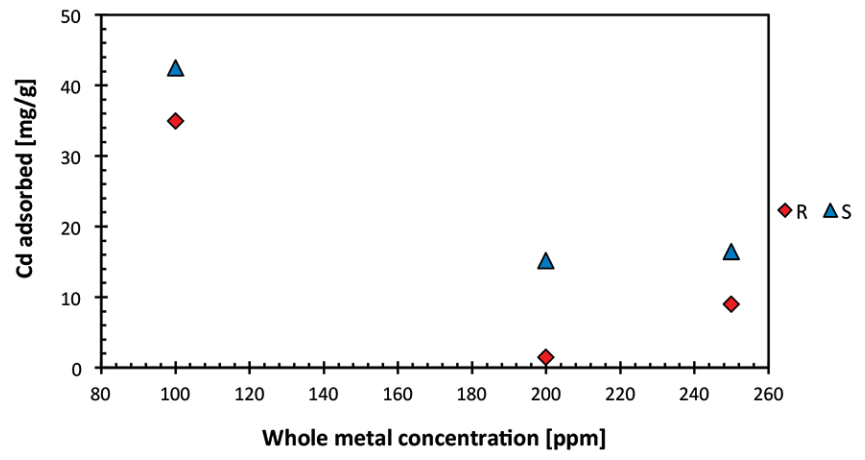

Figure 10-Effect of whole solution concentration on the adsorption of $\mathrm{Cd}$ with (R) NT biochar, and (S) PT biochar with SDS

validating the use of SDS impregnation in the removal of cadmium from aqueous mine tailings solutions.

\section{Conclusion}

Spent coffee grounds were successfully converted into biochar using hydrothermal methods. It was proven by SEM-EDS that SDS surfactant impregnation of the biochar is possible, creating suitable binding groups that can be identified with FTIR analysis. The isothermal study revealed that the adsorption process occurred through a combination of homogeneous and heterogeneous mechanisms, while the kinetic study confirms the suitability of the pseudo-second-order model for the prediction of the adsorption capacity, allowing the PT biochar to be recognized as the best adsorbent, with a capacity of $q_{e}=$ $10.67 \mathrm{mg} / \mathrm{g}$ compared to the NT biochar with a capacity of $q_{e}=$ $4.82 \mathrm{mg} / \mathrm{g}$. The thermodynamic study showed that the adsorption of cadmium on the PT biochar was a spontaneous process which took place through a chemisorption mechanism. Application of the biochars to coal tailings leachate was more successful at lower total metal feed concentrations, with the PT biochar outperforming the NT biochar. Spent coffee grounds, which is seen as a waste product in most societies, could therefore be beneficiated to form biochar and applied for effective treatment of mine wastewater contaminated with cadmium.

\section{Acknowledgements}

The authors appreciate the sponsorship from North-West University, the contributions of Mr N. Lemmer from the NorthWest University, as well as Ms Nomsa Baloyi and Mr Edward Malenga from the University of Johannesburg.

\section{References}

Cheng, S., Liu, G., Zhou, C., and Sun, R. 2018. Chemical speciation and risk assesment of cadmium in soils around a typical coal mining area of China. Ecotoxicology and Environmental Safety, vol. 160. pp. 67-74.

Dudka, S., Piotrowska, M., ChlopeckA, A., and Wiтек, T. 1995. Trace-metal contamination of soils and crop plants by the mining and smelting industry in upper Silesie, South Poland. Journal of Geochemical Exploration, vol. 52, no. $1-2$. pp. 237-250.

Fosso-Kankeu, E., Mittal H., WaAnders, F., and Ray, S.S. 2017b. Thermodynamic properties and adsorption behaviour of hydrogel nanocomposites for cadmium removal from mine effluents. Journal of Industrial and Engineering Chemistry, vol. 48. pp. 151-161.

Fosso-KanKeu, E., WAanders, F., Lemmer, N., and Steyn, R.H. 2017a. Surfactant Impregnated bentonite clay for the removal of heavy metals from solution. Proceedings of the 9th International Conference on Advances in Science, Engineering, Technology \& Waste Management (ASET WM-17), Parys, South Africa, 27-28 November 2017. Waanders, F., Fosso-Kankeu, E., Topcuoglu, B., Plaisent, M., and Thaweesak, Y. (eds). pp. 54-63.

Fosso-Kankeu, E., WaAnders, F., and Fourie, C.L. 2016. Adsorption of Congo Red by surfactant-impregnated bentonite clay. Desalination and Water Treatment, vol. 57. pp. 27663-27671. doi: 10.1080/19443994.2016.1177599

Fosso-Kankeu, E., MitTal, H., Mishra, S.B., and Mishra, A.K. 2015. Gum ghatti and acrylic acid based biodegradable hydrogels for the effective adsorption of cationic dyes. Journal of Industrial and Engineering Chemistry, vol. 22, pp.171-178.

Fu, F. and WANG, Q. 2011. Removal of heavy metal ions from wastewater: a review. Journal of Environmental Management, vol. 92. pp. 407-418.

Jin, H.P., Mansour, E., and Thomas, B. 2017. A practical testing approach to predict the geochemical hazards of in-pit coal mine tailings and rejects. CATENA, vol. 148. pp. 3-10.

Jusoh, A., Shiung, L.S., Ali, N., and Noor, M.J.M.M. 2007. A simulation study of the removal efficiency of granular activated carbon on cadmium and lead. Desalination, vol. 206. pp. 9-16.

KAnG, K.C., KIM, S.S., ChoI, J.W., and Kwon, S.H. 2008. Sorption of $\mathrm{Cu}^{2+}$ and $\mathrm{Cd}^{2+}$ onto acid- and base-pre-treated granular activated carbon and activated carbon fiber samples. Journal of Industrial and Engineering Chemistry, vol. 14. pp. 131-135.

KANTCHEVA, M. 2003. FT-IR spectroscopic investigation of the reactivity of NOx species adsorbed on $\mathrm{Cu}^{2+} / \mathrm{ZrO}_{2}$ and $\mathrm{CuSO}_{4} / \mathrm{ZrO}_{2}$ catalysts toward decane. Applied Catalysis B: Environmental, vol. 42. pp. 89-109.

Marouez, J., Pourret, O., Faucon, M., Weber, S., Hoang, T., and Martinez, E. 2018. Effect of cadmium, copper, and lead on the growth of rice in the coal mining region of Quang Ninh, Cam-Pha (Vietnam). Sustainability, vol. 10, no. 6. p. 1758 . doi: $10.3390 / \mathrm{su} 10061758$

Mohan, D., Prachi, S., Ankur, S., Phillip, H.S., and Charles, P.J. 2015. Lead sorptive removal using magnetic and nonmagnetic fast pyrolysis energy cane biochars . Journal of Colloid and Interface Science, vol. 448. pp. 513-528.

Redwscu, A. and Nicolae, A. 2012. Adsorption of $\mathrm{Zn}, \mathrm{Cu}$ and $\mathrm{Cd}$ from waste waters by means of maghemite nanoparticles. UPB Scientific Bulletin, Series B: Chemistry and Materials Science, vol. 74. pp. 255-264.

Salomons, W. 1995. Environmental impact of metals derived from mining activities: Processes, predictions, prevention. Journal of Geochemical Exploration, vol. 52. pp. 5-23.

Yao, Y., Gao, B., Fang, J., Zhang, M., Chen, H., Zhou, Y., Creamer, A.E., Sun, Y., and YANG, L. 2014. Characterization and environmental applications of clay-biochar composites. Chemical Engineering Journal, vol. 242. pp. 136-143.

Zuorro, A. and LAVEcCHIA, R. 2012. Spent coffee grounds as a valuable source of phenolic compounds and bioenergy. Journal of Cleaner Production, vol. 34. pp. 49-56.

Table $V$

Thermodynamic properties

\begin{tabular}{|c|c|c|c|c|c|}
\hline Adsorbent & Ka & Temperature (K) & $\Delta G(\mathrm{~kJ} / \mathrm{mol})$ & $\Delta S(\mathrm{~J} / \mathrm{mol} / \mathrm{K})$ & $\Delta H(\mathrm{~kJ} / \mathrm{mol})$ \\
\hline $\begin{array}{c}\text { NT biochar } \\
0.1406 \\
0.1532\end{array}$ & $\begin{array}{c}0.1071 \\
318 \\
328\end{array}$ & $\begin{array}{c}308 \\
3822.43 \\
3569.08\end{array}$ & 4075.79 & 25.3 & 11879 \\
\hline $\begin{array}{c}\text { PT biochar } \\
1.1420 \\
1.2443\end{array}$ & $\begin{array}{c}1.0941 \\
318 \\
328\end{array}$ & $\begin{array}{c}308 \\
-392.60 \\
-574.21\end{array}$ & -210.98 & 18.2 & 5382 \\
\hline
\end{tabular}

